\title{
Identificación taxonómica de arvenses presentes en el cultivo de palma aceitera
}

\author{
Santillán, Fernanda ${ }^{\text {a* }}$ - Ramos, Soledad ${ }^{\mathrm{b}}$ - Arias, Diego a \\ a Dirección de Servicios de Laboratorios - AGROCALIDAD. Vía Interoceánica km 14, Granja del MAGAP, Tumbaco-Ecuador \\ ${ }^{b}$ Proyecto Prometeo - SENESCYT. 9 de Octubre N22-48 y Jerónimo Carrión, Quito-Ecuador

\section{RESUMEN}

Las arvenses son plantas que aparecen en los cultivos, de ellas se ha destacado por mucho tiempo su papel perjudicıal, Inter firıendo en el crecimiento, desarrollo y prodüčcion.' Sın 'embargo otras son beneficiosas, siendo hóspedėras de enemigos naturales de determi-nadas plagas. El objetivo de este estudio fue determi-nar las arvenses presentes en el cultivo de palma acei-tera (Elaeıs guineensıs Jacq). Fueron identificadas un total de 241 mu estras, córrespondientes a 138 espe-cies. El material fue recolectado en diversas fincas palmèras situadas en las provincias de Esmeraldas

Guayas, Manabí, Orellana, Santo Domingo y Sucum- bıos. En este estudıo se ha encontrado que la familia P'oaceae es la mejor' representada, seguida de Astera-ceae, Solanaceae, Cyperaceae, Euphorbiaceae, Faba-ceae y Rubiaceae como las familias con una mayor presencia entre las arvenses en palma. Las plantas fueron identifıcadas con la ayuda de claves taxonómicas de' la 'Fllora de Ecuador y América Latina, y fınalmente conservadas en el Herbario de AGROCALIDAD como constancia de este estudio así como para realizar intercomparaciones y futuros estudios moleculares.

Palabras clave: Arvenses, Elaeis guineensis Jacq., herbarıo, Identıfıcacıon taxonómica, palma aceitera.

\footnotetext{
* Correspondencia a: Agencia Ecuatoriana de Aseguramiento de la Calidad del Agro - AGROCALIDAD, km 14. Vía Interoceánica Granja del MAGAP, Tumbaco, Ecuador. Teléfono: 59322372845.

Correo electrónico: maria.santillan@agrocalidad.gob.ec
} 